\title{
The Hepatoprotective Effects of Vitamin $C$ and Micronized Vitamin $C$ against Paracetamol Induced Hepatotoxicity in Rats: A Comparative Study
}

\author{
K. M. A. Hassnin, K. S. Hashem \\ Department of Biochemistry, Faculty of Veterinary Medicine, Beni-Suef Universit, Beni-Suef, Egypt
}

\begin{abstract}
Micronization of chemical compounds is a new promising field as it reduces the size of the particles thus it increases their penetration power. Many theories prove that micronized particles are more effective even in very low concentration as compared to its normal size. Paracetamol is a commonly used effective analgesic and antipyretic agent for relief of mild and moderate pain. However, deliberate overdose or accidental overdose can cause hepatotoxicity. In the present study, we have evaluated and compared between the hepatoprotective and antioxidant effects of vitamin $\mathrm{C}$ and micronized vitamin $\mathrm{C}$ against paracetamol induced hepatotoxicity in rats. Activities of liver enzymatic markers (Alanine amino transferase "ALT", Aspartate amino transferase "AST", Alkaline Phosphatase "ALP") and total protein "TP" concentration were estimated in serum. Lipid peroxidation "MDA" and antioxidant status (reduced glutathione "GSH" concentration, glutathione reductase "GR", catalse and super oxide dismutase "SOD" activities) were measured in tissue homogenates. Paracetamol administration $(600 \mathrm{mg} / \mathrm{Kg}$ B.wt.) significantly increased the liver enzymatic markers and decreased the total protein level. It also increased hepatic lipid peroxidation "MDA" and the activities of both catalase and SOD while it decreased GSH content and glutathione reductase (GR) activity. Treatment of vitamin $C$ and micronized vtamin $C$ restore the measured parameters nearly to their normal levels. Finally, micronized vitamin $C$ has a more potent effect than ordinary vitamin $C$.
\end{abstract}

Paracetamol or acetaminophen is a widely used analgesic (pain reliever) and antipyretic (fever relief) all over the world. It is commonly used for the relief of headaches, other minor aches and pains, and is a major ingredient in numerous cold and flu remedies. In combination with opioid analgesics, paracetamol can also be used in the management of more severe pain such as post surgical pain and providing palliative care in advanced cancer patients (Scottish, 2008). The onset of analgesia is approximately 11 minutes after oral administration of paracetamol, and its half-life is 1-4 hours. While generally safe for use at recommended doses $(1,000 \mathrm{mg}$ per single dose and up to $4,000 \mathrm{mg}$ per day for adults (Acetaminophen Drugs.com), acute overdoses of paracetamol can cause potentially fetal liver damage and, in rare individuals, a normal dose can do the same; the risk is heightened by alcohol consumption. Paracetamol toxicity is the foremost cause of acute liver failure in the Western world, and accounts for most drug overdoses in the United States, the United Kingdom, Australia and New Zealand (Khashab et al., 2007 and Daly et al., 2008).

Paracetamol is a part of the class of drugs known as "aniline analgesics"; it is the only such drug still in use today (Bertolini et al., 2006). It is classified as a nonsteroidal anti-inflammatory drug (NSAID) by some authors (Hillier et al., 2001), and not as an NSAID by others, (Acetaminophen. chemicall and 21.com 2011) while most sources implicitly distinguish them, for example by mentioning both NSAIDs and paracetamol in the same sentence. Paracetamol has few anti-inflammatory effects in comparison to NSAIDs. However, aspirin, paracetamol and other NSAIDs all act by the same mechanism (inhibition of prostaglandin synthesis) and all show varying levels of analgesic, antiinflammatory, antipyretic and antiplatelet actions (Byrant et al., 2007).

Ascorbic acid (AA) is a naturally occurring, water-soluble compound with desirable characteristics as an enzyme inhibitor. It is the most abundant antioxidant in plants, and is used in agriculture to enhance plant stress-resistance (Smirnoff, 2000).

Ascorbic acid or vitamin $\mathrm{C}$ is a widely distributed in many natural products. Mostly rich in fresh fruits and leafly vegetables (Haytowitz, 1995). Vitamin C is one of the most important water soluble antioxidant in plants, animal, and human (Mandle et al., 2009). Acharya et al., (2008) demonstrated that ascorbic acid reduces 
oxidative stress in many tissues exposed to oxidative stress.

Ascorbic acid (vitamin C) and its derivatives are not endogenously produced and must be obtained from dietary sources. Ascorbic acid is a major cellular antioxidant and is known to promote collagen expression, wound healing and, when applied topically, is capable of protecting the skin against ultraviolet (UV) light exposure, although it is not a sunscreen (Colvon and Pinnell, 1996).

Micronization is the process of reducing the average diameter of a solid material's particles. Usually, the term micronization is used when the particles that are produced are only a few micrometers in diameter. Traditional micronization techniques are based on friction to reduce particle size. Such methods include milling, bashing and grinding. Methods like crushing and cutting are also used for reducing particle diameter, but produce more rough particles. Crushing employs hammer-like tools to break the solid into smaller particles by means of impact. Cutting uses sharp blades to cut the rough solid pieces into smaller ones. Modern methods use supercritical fluids in the micronization process. The most widely applied techniques of this category include the RESS process (Rapid Expansion of Supercritical Solutions), the SAS method (Supercritical AntiSolvent) and the PGSS method (Particles from Gas Saturated Solutions) (Wikimedia foundation, 2012).

Micronization enhances the solubility and the bioavailability of many compounds by increasing the dissolution rate of these compounds (Micron technologics, 2011).

\section{Material and methods}

Chemicals. Paracetamol: was purchased as a commercial drug (Novaldol 1000) ${ }^{\mathrm{R}}$. Vitamin C was purchased from Sigmaadlrich. Micronized vitamin C was purchased from Cophavet Company, Egypt.

Experimental animal. This study was approved by the Committee of Scientific Ethics at BeniSuef University, Egypt, and was carried out in accordance with its guidelines for animal use.

Twenty male Albino Wistar rats weighing 200-250 grams were used in this study. They were obtained from the animal house of the research institute of ophthalmology (El-Giza, Egypt). They were kept under suitable conditions for one week for adaptation. They were maintained in stainless steel cages in a wellventilated animal house at normal temperature $\left(22 \pm 5^{\circ} \mathrm{C}\right)$ under $12: 12 \mathrm{~h}$ light dark cycle. They were fed with standard diet and given water ad libitum. The rats were maintained under standard conditions in an animal house as per the guidelines of Beni-Suef University Committee for the Purpose of Control and Supervision on Experiments on Animals. Rats were randomly divided into four equal groups (5 rats each) as follows.

First group. This group served as control and was orally given a dose of sterile phosphatebuffered physiological saline $(0.5 \mathrm{~mL})$ in two successive doses 24 hours interval.

Second group (paracetamol treated group). Rats were orally given paracetamol (Acetaminophen, APAP) at a dose of $600 \mathrm{mg} / \mathrm{kg}$ body weight (Novaldol 1000) in two doses with 24 hours interval.

Third group (vitamin C-paracetamol treated group). Rats were orally administered vitamin $\mathrm{C}$ at a dose of $500 \mathrm{mg} / / \mathrm{kg}$ body weight every 24 hours for six successive days and they were also orally given paracetamol at a dose of $600 \mathrm{mg} / \mathrm{kg}$ body weight on the third and fourth days of administration.

Fourth group (micronized vitamin Cparacetamol treated group). Rats were orally administered micronized vitamin C $500 \mathrm{mg} / \mathrm{kg}$ body weight every 24 hours for six successive days and they were also orally given paracetamol at a dose of $600 \mathrm{mg} / \mathrm{kg}$ body weight on the third and fourth days of administration. The rats of all groups were scarified after 24 hours of the last administration.

Sampling. Blood samples were collected from the eye venous plexus of all animals for serum preparation after an overnight fasting.

Biochemical studies. The following parameters were measured in either the serum of the four tested rat groups according to the instructions of their referred methods; serum AlT, AST, ALP activities and total protein concentration were measured by using Daimon measuring kits. After scarification of rats, liver was collected and kept in the deep freeze for Homogenization. Homogenization was done by measuring $0.5 \mathrm{gm}$ of liver in $5 \mathrm{ml}$ normal saline and then homogenized in a homogenizer (ORTOALRESA). The homogenates were centrifuged at $1000 \mathrm{~g}$ for 15 minutes. The supernatants were collected in epindorff tubes that were kept in the deep freezer (at $-20^{\circ} \mathrm{C}$ ) for futher biochemical investigations. Reduced glutathione (GSH) content, Catalase, superoxide dismutase (SOD) activity and Malondialdehyde 
(MDA) were measured in tissue homogenates by using Bio diagnostic colorimetric assay kits (Biodiagnostic, Cairo, Egypt). Liver DNA fragmentation was calculated as \% (Singh et al., 1988).

\section{Results and discussion}

Our results showed that when rats were given paracetamol "APAP" orally in a dose of $600 \mathrm{mg} / \mathrm{kg}$ body weight every 24 hours for two doses, it caused a significant increase in activities of liver enzymes (ALT, AST and ALP activities) when compared to rats of control group (Table 1). In addition, APAP administration caused a marked decrease in total proteins (Table 1). These findings supported the liver damage effect of APAP taking in consideration that liver is the main factory for albumin synthesis which represents the most fraction of serum total proteins. These findings come in agreement with Kanbur et al., (2009) who found that administration of APAP caused a significant release of liver enzymes into circulation. Similarly, in experimental acute APAP intoxications, the serum ALT, AST and ALP activities were increased (Kupeli et al., 2006). Paracetamol (PAR) is one of the commonest drugs used for the treatment of minor to moderate pain in humans. However, the intake of a single dose of $10 \mathrm{~g}$ or higher often causes centrolobular liver necrosis (Melli and Kayaalp, 2006). In case of intake high doses, PAR is first converted into non-reactive metabolites in the liver by sulphation and glucuronidation reactions. However, these metabolites are later converted into a reactive metabolite known to be toxic for the liver, namely $\mathrm{N}$-acetyl-p-benzo-quinoneimine, by the liver cytochrom P-450 enzyme system. The resulting metabolite covalently binds to oxidized lipids and sulphydryl groups of the liver tissue, and thereby leads to the severe damage of cell membranes (Kupeli et al., 2006).

The major finding observed by APAP intoxication in humans and animals is acute centrolobular necrosis (MacNaughton, 2003). As ALT is an enzyme specific to liver damage, and is used routinely for the determination of liver damage (Turgut, 2000), the observed increase in the serum ALT activity is considered to be a significant indicator of APAP-induced acute liver damage (Sener et al., 2005).

In experimental acute APAP intoxications, in addition to ALT activity, serum AST and ALP activities were also increased (Sener et al., 2005; Kupeli et al., 2006).

In addition, our results showed that administration of APAP caused a significant increase in hepatic lipid peroxiadtion level (MDA), depletion of GSH contents (Table 2) and decreased GR activity (Table 3 ) as compared to that of rats of control group. Added to that, giving APAP caused a significant increase in hepatic catalase "CAT" (Table 2) and SOD (Table 3) activities. These findings come in agreement with the results obtained by Abdelmegeed et al., (2010) who reported that APAP caused a direct hepatic centrolobular necrosis consequently, causing a marked alteration in the hepatic antioxidant defense mechanism. Moreover, our findings coincide with those reported by Manimaran et al., (2010) who found that acetaminophen induced hepatic oxidative damage and alteration of hepatic GSH contents, GR and GPXs activities.

Moling et al., (2006) reported a severe hepatotoxicity after therapeutic doses of acetaminophen in an adult man. Hepatotoxicity of acetaminophen is linked to its oxidative biotransformation in liver to the reactive metabolite $\mathrm{N}$-acetylp- benzoquinoneimine (NAPQI) by different cytochrome-P450 (CYP) isoforms (Bertolini et al., 2006). There are many modern explanations for APAP hepatic toxicity, Kim et al., (2007) stated that acetaminophen depleted the CYP level and increased the activities of CYP3A4-mediated indicating that these enzymes played a significant role in the disposition and bioactivation of acetaminophen.

Table (1): Changes in serum ALT, AST, ALP activities and total proteins concentration in response to paracetamol, vitamin $\mathrm{C}$ and micronized vitamin $\mathrm{C}$ administration.

\begin{tabular}{lcccc}
\hline Animal group & ALT (U/L) & AST (U/L) & ALP(U/L) & Total proteins (g/dI) \\
\hline $\begin{array}{l}\text { Control group } \\
\text { Paracetamol treated group }\end{array}$ & $19.48 \pm 0.62^{\mathrm{a}}$ & $49.6 \pm 2.2^{\mathrm{a}}$ & $95.08 \pm 2.9^{\mathrm{a}}$ & $5.7 \pm 0.18^{\mathrm{a}}$ \\
$\begin{array}{l}\text { Paracetamol - treated vitamin C } \\
\text { group }\end{array}$ & $64.97 \pm 3.24^{\mathrm{b}}$ & $150 \pm 13.6^{\mathrm{b}}$ & $190.5 \pm 4.5^{\mathrm{b}}$ & $2.36 \pm 0.44^{\mathrm{b}}$ \\
$\begin{array}{l}\text { Paracetamol - treated micronized } \\
\text { vitamin C group }\end{array}$ & $21.26 \pm 2 . \mathrm{g}^{\mathrm{a}}$ & $76.5 \pm 4.2^{\mathrm{c}}$ & $110.4 \pm 2.9^{\mathrm{c}}$ & $3.85 \pm 0.28^{\mathrm{c}}$ \\
\hline
\end{tabular}

Data are presented as mean values and standard errors $( \pm)$, mean values with different superscript letters mean a significant deference at $\mathrm{P}<0.05$. 
It is believed, when $70 \%$ of hepatic GSH is consumed, NAPQI (the reactive metabolite of acetaminophen) becomes available for inducing a cascade that may result in hepatic cell death (Larson, 2007; Manimaran et al., 2010). Acetaminophen reduced hepatic GSH by 60 $90 \%$, indicating inefficient detoxification of NAPQI and its eventual availability for interaction with the cellular macromolecules. The balance between cellular GSH and GSSG is maintained by GR. The involvement of GSHdependent GPx in GSH depletion may be ruled out as both arsenic and acetaminophen reduced its activity. It is known that arsenate and NAPQI have high affinity for GSH. Moreover, GSH is consumed for detoxification of ROS and peroxides produced. Therefore, conjugation of GSH with these electrophiles and free radicals could be another cause for GSH depletion. Acetaminophen mediated increase in SOD activity indicates the occurrence of oxidative stress. This coupled with the reductions in GR and increased CAT activities, that neutralize $\mathrm{H}_{2} \mathrm{O}_{2}$, imply accumulation of $\mathrm{H}_{2} \mathrm{O}_{2}$ and more production of the ultimate toxicant hydroxyl radical $\left(\mathrm{OH}^{-}\right)$via Fenton reaction. The increase in LPO, a free radical-dependent mechanism, further supports the excess generation of intracellular ROS - considered as a critical event in the development of acetaminophen hepatotoxicity (Larson, 2007).

Drug induced liver injury caused by paracetamol (APAP) overdose is a primary cause of liver failure throughout the world. $N$-Acetyl $p$ benzoquinone (NAPQI), a toxic metabolite formed as a result of APAP metabolism is

Table (2): Changes in liver reduced glutathione (GSH), catalase and malonaldhyde (MDA) in response vitamin $\mathrm{C}$ and micronized vitamin $\mathrm{C}$ administration.

\begin{tabular}{lccc}
\hline Animal groups & $\begin{array}{c}\text { Liver GSH } \\
(\mathbf{m g} / \mathbf{g m} \text { tissue) }\end{array}$ & $\begin{array}{c}\text { Liver catalase } \\
(\mathbf{U} / \mathbf{L})\end{array}$ & $\begin{array}{c}\text { Liver MDA } \\
\text { (nmol/gm tissue) }\end{array}$ \\
\hline Control group & $68.26 \pm 1.8^{\mathrm{a}}$ & $2.31 \pm 2.8^{\mathrm{a}}$ & $28.6 \pm 0.82^{\mathrm{a}}$ \\
Paracetamol treated group & $34.02 \pm 3.12^{\mathrm{b}}$ & $6.6 \pm 0.38^{\mathrm{b}}$ & $55.76 \pm 4.7^{\mathrm{b}}$ \\
Paracetamol - vitamin C group & $50.28 \pm 1.77^{\mathrm{c}}$ & $3.89 \pm 0.37^{\mathrm{c}}$ & $41.24 \pm 1.06^{\mathrm{c}}$ \\
Paracetamol - micronized vitamin C group & $65.62 \pm 1.89^{\mathrm{a}}$ & $2.38 \pm 0.23^{\mathrm{a}}$ & $28.56 \pm 0.48^{\mathrm{a}}$ \\
\hline
\end{tabular}

Data are presented as mean values and standard errors $( \pm)$, mean values with different superscript letters mean a significant deference at $\mathrm{P}<0.05$.

Table (3): Changes in liver superoxide dismutase (SOD) and glutathione reductase (GR) activities in response to paracetamol, vitamin $\mathrm{C}$ and micronized vitamin $\mathrm{C}$ administration.

\begin{tabular}{lcc}
\hline Animal groups & Liver SOD (U/gm tissue) & Liver GR (U/gm tissue) \\
\hline Control group & $113.2 \pm \mathbf{4 . 6 9}^{\mathrm{a}}$ & $352.9 \pm \mathbf{1 4 . 1 6}^{\mathrm{a}}$ \\
Paracetamol treated group & $\mathbf{3 2 2 . 5} \pm \mathbf{1 2 . 6 9}^{\mathrm{b}}$ & $123.9 \pm \mathbf{1 1 . 2 2}^{\mathrm{b}}$ \\
Paracetamol - vitamin C group & $227.9 \pm \mathbf{1 3 . 3 6}^{\mathbf{c}}$ & $266.3 \pm \mathbf{1 4 . 5 9}^{\mathbf{c}}$ \\
Paracetamol - micronized vitamin C group & $125 \pm \mathbf{7 . 2 6}$ & $\mathbf{3 2 6 . 6}^{\mathrm{a}} \pm \mathbf{1 5 . 3 7}^{\mathrm{a}}$ \\
\hline
\end{tabular}

Data are presented as mean values and standard errors $( \pm)$, mean values with different superscript letters mean a significant deference at $\mathrm{P}<0.05$.

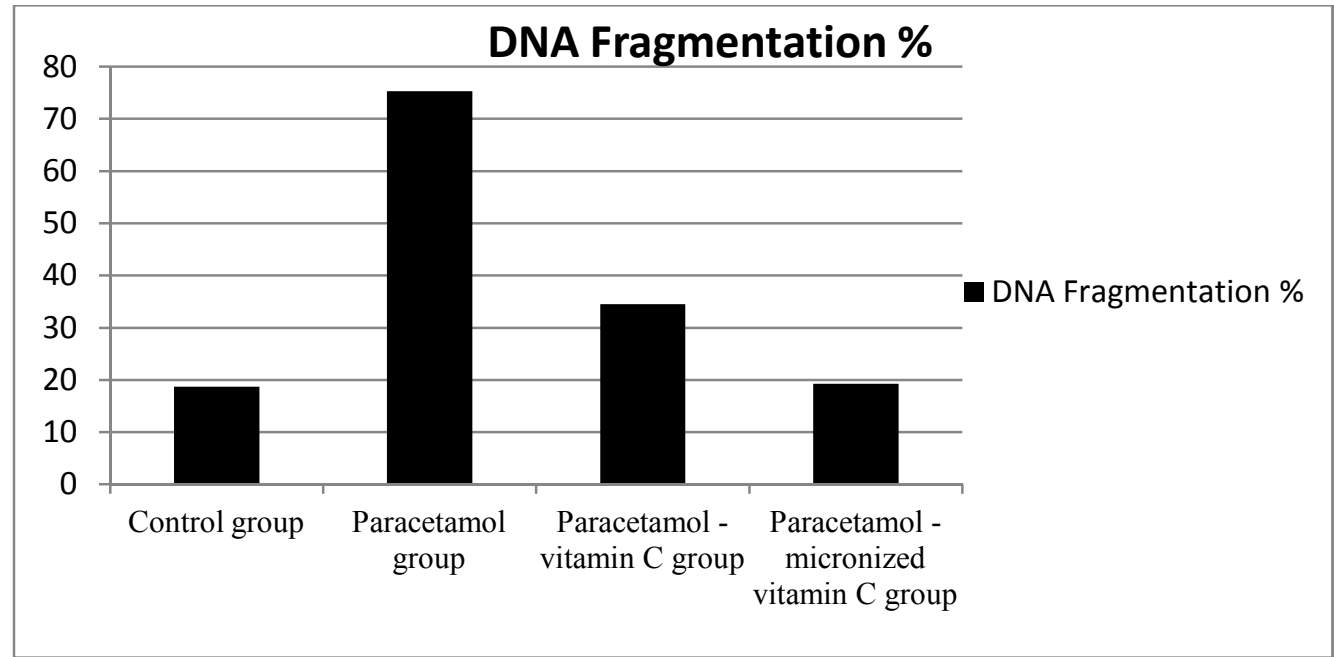

Figure (1): Changes in liver DNA fragmentation in response to paracetamol, vitamin $\mathrm{C}$ and micronized vitamin C administration 
detoxified by glutathione (GSH) to form APAPGSH adducts. Hence a toxic dose of APAP causes a $90 \%$ depletion of total hepatic GSH level and as a result the metabolite binds to cysteine in protein, forming acetaminophen proteins adducts (Cohen and Khairallah., 1997). However, once GSH reserves are depleted, multiple perturbations ensure that ultimately culminate in cell death. Events that produce hepatocellular death following APAP application are poorly understood. Another possible mechanism of APAP induced cell death is that covalent binding to cellular proteins results in subsequent loss of activity or function and eventual cell lysis. Primary targets have been concluded to be mitochondrial proteins, with resulting loss of energy production as well as proteins involved in cellular ion control (Nelson, 1990).

A study conducted by Ghosh and Sil, (2007) showed the involvement of oxidative stress with a concurrent depletion of glutathione in mouse liver.

APAP caused a significant increase in hepatocytes DNA damage as compared to normal rats (Fig. 1). These results are agreed with Ghosh and Sil, (2009) who reported that DNA damage caused by oxygen-derived species including free radicals can produce a multiplicity of modifications in DNA including base and sugar lesions, strand breaks, DNA-protein crosslinks and base-free sites. If left unrepaired, oxidative DNA damage can lead to detrimental biological consequences in organisms, including cell death, mutations and transformation of cells to malignant cells. Our findings are in parallel to those recorded by Ramachandran et al., (2011) who found that administration of APAP caused a significant increase in DNA fragmentation.

DNA fragmentation is a hallmark of APAP hepatotoxicity (Gujral et al., 2002). The frequently reported DNA ladder formation suggests that the DNA fragmentation is an endonuclease-mediated process (Cover et al., 2005). The absence of caspase activity during APAP hepatotoxicity (Jaeschke et al., 2006) excludes the involvement of the caspaseactivated DNase, which is the classical endonuclease responsible for apoptotic DNA fragmentation (Nagata et al., 2003). Ramachandran et al., (2011) showed that translocation of AIF and endonuclease G from the mitochondria to the nucleus as being critical for DNA damage (Bajt et al., 2006). In addition, lysosomal DNasel may also be involved at later time points (Napirei et al., 2006). The mitochondrial release of AIF and endonuclease $\mathrm{G}$ is facilitated by the initial formation of Bax pores and later by mitochondrial matrix swelling and rupture of the outer membrane (Bajt et al., 2008). AIF in the cytosol suggests that the enhanced mitochondrial release of AIF was at least in part responsible for the increased DNA damage. Interestingly, mitochondrial Bax translocation was only modestly affected indicating the main cause of the increased AIF release was not enhanced Bax pore formation. However, even in the absence of Bax, the mitochondrial oxidant stress and peroxynitrite formation was able to trigger the MPT with matrix swelling, which induced the accelerated release of AIF and endonuclease $\mathrm{G}$ and consequently nuclear DNA fragmentation (Bajt et al., 2008). Consistent with this conclusion, preventing the MPT pore formation by scavenging reactive oxygen and peroxynitrite (Bajt et al., 2006) or by eliminating cyclophilin $\mathrm{D}$, a critical regulator of the MPT pore, drastically reduced DNA damage (Ramachandran et al., 2011).

Based on these facts, we conclude that the accelerated DNA damage observed in APAP hepatotoxicity in rats is most likely caused by the enhanced MPT pore formation due to the enhanced oxidant stress and impaired defense mechanisms against reactive oxygen and nitrogen species.

Vitamin $\mathrm{C}$ is an essential nutrient involved in a large number of cellular processes (Arrigoni and Tullio, 2002). However, humans are unable to synthesize vitamin $\mathrm{C}$ and must therefore acquire it from diet. The main sources of dietary vitamin $\mathrm{C}$ in Chinese subjects are raw vegetables and fruits. The daily dietary intake of vitamin $\mathrm{C}$ in China is about $110 \mathrm{mg}$ (Zhang et al., 2004). Research into the functions of vitamin C (Lascorbic acid and dehydro-ascorbic acid) in vivo has been extensive, and in recent years has focused on its role as a powerful plasma antioxidant capable of reducing the oxidative stress effects of various diseases (SanchezMoreno et al., 2004). For instance, vitamin $C$ has been shown to significantly improve endothelium-dependent vasodilatation among diabetics and among patients with coronary artery disease, possibly by reducing excess superoxide production and decreasing the levels of nitric oxide inactivation (Uscio et al., 2003). Physiologic concentrations of vitamin $\mathrm{C}$ can inhibit low-density-lipoprotein (LDL) oxidation 
and thus inhibits the free radicals formation and reactive oxygen species (ROS) (Bernard et al., 2003). Our results showed that administration of vitamin $\mathrm{C}$ decreased activities of liver enzymes in serum as compared to paracetamol group (Table 1). In addition, vitamin $\mathrm{C}$ modulated the antioxidant status of liver by increasing GSH content and decreasing the LPO level (Table 2), catalase (Table 2) and SOD activities (Table 3). Moreover, vitamin $\mathrm{C}$ administration returned the DNA fragmentation $\%$ of the Paracetamolvitamin $\mathrm{C}$ treated group to nearly that of the control group.

Administration of micronized vitamin $\mathrm{C}$ showed a significant decreased activities of liver enzymes (ALT, AST and ALP)in serum and marked increase of serum total protein as compared to ordinary vitamin $\mathrm{C}$ group (Table 1). Moreover, Micronized vitamin $\mathrm{C}$ posses more protective effect against APAP hepatic induced oxidative damage through increasing GSH concentration, (Table 2) and activity of GR (Table 3), decreasing activities of catalase, SOD and MDA concentration. In addition, micronized vitamin $\mathrm{C}$ has a more potent effect on DNA fragmentation that ordinary vitamin $\mathrm{C}$ (Fig. 1). Our study revealed that micronized vitamin $\mathrm{C}$ retained the measured hepatotoxic markers into its normal ranges. The more protective effect of micronized vitamin $\mathrm{C}$ could be contributed to the benefits of micronization as micronization increases the bioavailability of vitamin $\mathrm{C}$ than ordinary macromolecule. This work is a novel as there is a very few available literature about the application and uses of micronized vitamin $\mathrm{C}$.

\section{Acknowledgment}

Authors acknowledge the authority of Faculty of Veterinary Medicine, Beni-Suef University for their financial support. We also acknowledge the staff members of Biochemistry department, veterinary Faculty of Veterinary Medicine, Beni-Suef University for their valuable help.

\section{References}

Abdelmegeed, M.; Kwan, H. M.; Chi, C.; Frank, J. G. and Song, B. J. (2010): Role of cytochrome P450 2E1 in protein nitration and ubiquity-mediated degradation during acetaminophen toxicity.Biochem Pharmacol, 79: 57-66. Acharya, U. R.; Mishra, M.; Patro, J. and Pana, M. K. (2008): Effect of vitamin $C$ and $E$ on spermatogensis in mice exposed to cadmium. Reprod Toxicol 25: 84-88.

Arrigoni, O. and De Tullio, M. C. (2002): Ascorbic acid much more than just an antioxidant. Biochim Biophys Acta; 1569: 1-9.

Bajt, M. L.; Cover, C.; Lemasters, J. J. and Jaeschke, H. (2006): Nuclear translocation of endonuclease $G$ and apoptosis-inducing factor during acetaminophen-induced liver cell injury, 94: 217-225.

Bajt, M. L.; Farhood, A.; Lemasters, J. J. and Jaeschke, H. (2008): Mitochondrial bax translocation accelerates DNA fragmentation and cell necrosis in a murine model of acetaminophen hepatotoxicity, 324: 8-14.

Bernard, D.; Christophe, A.; Delanghe, J.; Langlois, M.; De Buyzere, M. and Comhaire, F. (2003): The effect of supplementation with an antioxidant preparation on LDLoxidation is determined by haptoglobin polymorphism. Redox Rep, 8: 41-46.

Bertolini, A.; Ferrari, A.; Ottani, A.; Guerzoni, S.; Tacchi, R. and Leone, S. (2006): Paracetamol: new vistas of an old drug (PDF). CNS Drug Rev., 12, 250-275.

Byrant, B.; Knights, K. and Salerno, E. (2007): Pharmacology for health professionals. Elsevier. p. 270. ISBN 9780729537872.

Cohen, S. D. and Khairallah, E. A. (1997): Selective protein arylation and acetaminopheninduced hepatotoxicity. Drug Metab. Rev., 29: 59-77.

Colvon, R. M. and Pinnell, S. R. (1996): “Topical Vitamin $\mathrm{C}$ in Aging" in Clinics in Dermatology, Skin Aging, and Photoaging, Antonio Ledo. Ed., 14: 227-234.

Cover, C.; Mansouri, A.; Knight, T. R.; Bajt, M. L.; Lemasters, J. J.; Pessayre, D. and Jaeschke, H. (2005): Peroxynitrite-induced mitochondrial and endonucleasemediated nuclear DNA damage in acetaminophen hepatotoxicity. J. Pharmacol. Exp. Ther., 315: 879-887.

Daly, F. F.; Fountain, J. S.; Murray, L.; Graudins, A. and Buckley, N. A. (2008): Guidelines for the management of paracetamol poisoning in Australia and New Zealand explanation and elaboration. A consensus statement from clinical toxicologists consulting to the Australasian poisons information centres". Med J. Aust., 188 (5): 296-301. PMID 18312195.

Ghosh, A., and Sil, P.C. (2007): Antioxidative effect of a protein from Cajanus indicus L. against Acetaminophen inducedhepato-nephrotoxicity. J. Biochem.Mol. Biol., 40: 1039-1049.

Gujral, J. S.; Knight, T. R.; Farhood, A.; Bajt, M. L. and Jaeschke, H. (2002): Mode of cell death after acetaminophen overdose in mice: apoptosis or oncotic necrosis? Toxicol. Sci., 67: 322-328.

Haytowitz, D. B. (1995): Information of USDA's nutrient Data Bank. J. Nutr. 125: 1952-1955.

Hillier, Keith; Waller, Derek J.; and Renwick, Andrew (2001): Medical pharmacology and therapeutics. Philadelphia: W.B. Saunders. ISBN 0-7020-2272-1.

Jaeschke, H.; Cover, C. and Bajt, M. L. (2006): Role of caspases in acetaminophen-induced liver injury, 78: 16701676.

Kanbur, M.; Gokhan, E.; Latife, B.; Sibel, S.; Bilal, C. L.; Sule, A. and Ayhan, A. (2009): The effects of royaljelly on liver damage induced by paracetamol in mice. Experimental and Toxicologic Pathology, 61: 123-132.

Khashab, M.; Tector, A. J. and Kwo, P. Y. (2007): Epidemiology of acute liver failure. Curr Gastroenterol Rep, 9 (1): 66-73.

Kim, S. N.; Seo, J. Y.; Jung, D. W.; Lee, M. Y.; Jung, Y. S. and Kim, Y. C., (2007): Induction of hepatic CYP2E1 by a subtoxic dose of acetaminophen in rats: increase in dichloromethane metabolism and carboxyhemoglobin elevation. Drug Metab Dispos, 35:1754-1758.

Kupeli, E.; Orhan, D. D. and Yesilada, E. (2006): Effectof Cistus laurifolius L. leaf extracts and flavonoids on a cetaminophen-induced hepatotoxicity in mice. Journal of Ethnopharmacology, 103: 455-460 
Laine, J.; Auriola, S.; Pasanen, M., and Juvonen, R., (2007): Acetaminophen bioactivation by CYP enzymes. Toxicol Lett, 172: S85.

Larson, A. M. (2007): Acetaminophen hepatotoxicity. Clin. Liver Dis., 11: 525-548.

MacNaughton, S. M. (2003): Acetaminophen toxicosis in a Dalmatian. Can Vet J; 44:142-144.

Mandl, J.; Szarka, A. and Banhegyi, G. (2009): Vitamin $\mathrm{C}$ update on physiology and pharmacology. $\mathrm{Br} \mathrm{J}$ pharmacol, 157: 1097- 1110

Manimaran, A.; Souvendra, N. S. and Palanisamy S. (2010): Influence of repeated preexposure to arsenic on acetaminophen-induced oxidative stress in liver of male rats., $48: 605-610$

Melli, M. and Kayaalp, O. (2006): Parasetamol. In: Kayaalp O, editor. Rasyonel Tedavi Yonu nden Tibbi Farmakoloji.Hacettepe- Tas; 849-851.

Micron technologies, (2011): WWW.microtech.com.

Moling, O.; Cairon, E.; Rimenti, G.; Rizza, F.; Pristera, R. V. and Mian, P. (2006): Hepatotoxicity after therapeutic doses of acetaminophen. Clin Ther, $28: 755-760$.

Nagata, S.; Nagase, H.; Kawane, K.; Mukae, N. and Fukuyama, H. (2003): Degradation of chromosomal DNA during apoptosis.Cell Death Differ., 10: 108-116.

Napirei, M.; Basnakian, A. G.; Apostolov, E. O. and Mannherz, H. G., (2006): Deoxyribonuclease laggravates acetaminophen-induced liver necrosis in male CD-1 mice. Hepatology, 43: 297-305.

Nelson, S. D. (1990): Molecular mechanisms of the hepatotoxicity caused by acetaminophen, Semin. Liver Dis., 10: 267-278.

Ramachandran, A.; Margitta, L.; Steven, A. W. and Hartmut, J. (2011): The impact of partial manganese superoxide dismutase (SOD2)-deficiency on mitochondrial oxidant stress, DNA fragmentation and liver injury during acetaminophen hepatotoxicity, 25: 226-233.

Sanchez-Moreno, C.; Dashe, J. F. and Scott, T. (2004): Decreased levels of plasma vitamin $\mathrm{C}$ and increased concentrations of inflammatory and oxidative stress markers after stroke. Stroke; 35: 163-8.

Scottish Intercollegiate Guidelines Network (SIGN) (2008): Scotland: National Health Service (NHS).

Sener, G.; Sehirli, O.; Cetinel, S.; Yegen, B. G.; Gedik, N. and Ayanoglu-Dulger, G. (2005): Protective effects of MESNA (2-mercaptoethane sulphonate) against acetaminophen-induced hepatorenal oxidative damage in mice. J Appl Toxicol, 25: 20-9

Singh, N. P.; McCoy, M. T.; Tice, R. R. and Schneider, E. L. (1988): A simple technique for quantitation of low levels of DNA damage in individual cells, Exp. Cell Res., 175: 184-191.

Smirnoff, N. (2000): Ascorbic acid: metabolism and functions of a multi-facetted molecule. Curr Opin Plant Biol, 3(3): 229-235.

Turgut K. (2000): Veteriner klinik laboratuar teshis kitabi.Konya;.p.179-201.

Uscio, L. V.; Milstien, S. and Richardson, D. (2003): Long-term vitamin $\mathrm{C}$ treatment increase vascular tetrahydrobiopterin levels and nitric oxide synthase activity. Circ Res; 92: 88 - 95.

Wikimedia

foundation

(2012):

http://en.wikipedia.org/wiki/ Micronization \#References ??

Zhang, M.; Lee, A. H. and Binns. C. W. (2004): Reproductive and dietary risk factors for epithelial ovarian cancer in China. Gynecol Oncol : 320-326. 